\title{
Surgical management of inverted papilloma; a single-center analysis of 247 patients with long follow-up
}

\author{
Oisín Bugter * D , Dominiek André Monserez, Floris Vincent Willem Joseph van Zijl, \\ Robert Jan Baatenburg de Jong and Jose Angelito Hardillo
}

\begin{abstract}
Background: Our aim was to review our management of inverted papilloma (IP), perform a recurrence analysis, and review the literature.

Methods: A retrospective analysis of 247 patients treated for an IP. Patients were grouped according to surgical approach, tumor presentation (primary, residual and recurrence) and Krouse-stage.

Results: Recurrence was observed in 20.3\%, 28.6\% and 35.1\% ( $p=0.017$ ) of the patients who underwent endoscopic, external and combined surgery, respectively. Recurrences occurred more often in residual than primary IP (36.9\% vs. $22.3 \%, p=0.021)$. Primary endoscopic surgery had a recurrence rate of $12.5 \%$, which was comparable to the recent literature $(11.2 \%, 161 / 1433)$.

Conclusions: The relatively high number of recurrences in this cohort is explained by the long follow-up and previous (incomplete) surgery in 61.5\% of the cases. The inferior outcome of residual IP underscores the importance of having a low threshold for preoperative biopsy in unilateral and atypical sinonasal disease.
\end{abstract}

Keywords: Inverted papilloma, Endoscopic surgery, Recurrence, Retrospective study, Follow-up

\section{Background}

Inverted papilloma (IP) is a benign tumor of the sinonasal cavities. It was first described by Ward more than 150 years ago as a follicular tumor involving the nasal bones [1]. It took until 1938 for Ringertz to recognize the characteristic endophytic growth pattern and introduce the term 'inverting papilloma' [2]. Since then many researchers have contributed to the extensive knowledge we now have on IP [3].

The incidence of IP ranges from 0.2 to 0.6 people diagnosed per 100,000 per year. The most frequently reported complaints are similar to those of sinonasal polyps: unilateral nasal obstruction and rhinorrhea. IP is most commonly diagnosed in the fifth and sixth decade of life and has a predilection for males with a ratio of 3:1 [4]. The exact etiology of IP is unclear, but there are indications that HPV infection plays a role in the progression of

\footnotetext{
* Correspondence: o.bugter@erasmusmc.n

Department of Otorhinolaryngology and Head and Neck Surgery, Erasmus MC, 's-Gravendijkwal 230, 3015 CE, Rotterdam, The Netherlands
}

inverted papilloma and confers an increased risk for recurrence and malignant transformation $[5,6]$. The frequency of IP in unsuspected sinonasal polyps is reported to be between 0.31 and $0.93 \%[7,8]$.

The standard treatment has always been surgery aimed at complete removal of the tumor. Its association with malignancies in $5-15 \%$ is one of the distinct characteristics of IP that endorses surgical treatment [9]. Other important features include its aggressive growth, that causes adjacent bone to locally erode, and its tendency to recur. Over the last decades endoscopic surgery has become the gold standard for the treatment of IP with many studies showing significantly better treatment outcome in patients treated endoscopically [9].

The aim of this study was to analyze the developments in our management of IP over the last three decades, in particular with regard to the recurrence rates and outcomes of treatment. All surgical approaches were reviewed, with an emphasis on endoscopic surgery. Whether the presentation of the tumor (primary, residual or recurrent) 
before surgery in our clinic would affect the recurrence rate also had our interest. Finally, a literature review of IP cohort studies was performed to compare with our surgical outcomes and recurrence rates.

\section{Methods}

The Ethics Committee of the Erasmus Medical Center, a tertiary referral medical center, stated that ethical permission was not required for this retrospective study.

We included 323 IP patients, of which 247 were included in the recurrence analysis, between January 1983 and December 2012. All patients were obtained from PALGA, a Dutch nationwide network and registry of histo- and cytopathology. All cases received surgical treatment, had a preoperative histopathological proven diagnosis of IP, and complete clinical information. Clinical data was assessed using the electronic medical records (CSC-iSOFT, Virginia, USA) and paper charts.

The IP was classified as a primary when no prior surgery was performed and diagnosis was confirmed by a simple biopsy. Patients with previous surgery were divided into two groups: residual and recurrent IP. Residual IP were defined as those who underwent functional endoscopic surgery for reasons other than IP, which was deemed as inadequate tumor surgery. Inverted papilloma diagnosis is this group was unexpected at postoperative histopathological examination. Recurrent IP were defined as those who underwent adequate tumor surgery in a different, non-academic hospital with the preoperative suspicion or diagnosis of IP. These patients were referred to us for revision surgery after diagnosis of a recurrence.

All patients underwent surgery by experienced head and neck surgeons. Surgical treatment was divided into three groups: endoscopic surgery (pure endonasal endoscopic approach), external surgery (e.g., Denker, lateral rhinotomy, osteoplastic flap) and combined approaches (endoscopic surgery combined with Caldwell-Luc). The extent of surgery and approach were chosen based on the perceived origin and extent of the IP. In the endoscopic group, we mainly performed a medial maxillectomy, including (at least the posterior two thirds of) the inferior turbinate and an ethmoidectomy. We opted for a radical ethmoidectomy, including middle turbinate and opening of the frontal recess, for tumors limited to the ethmoid and/or frontal recess. For the external approach, we mainly performed a classic Denker (medial maxillectomy via opening of the anterior wall of the maxillary sinus, complete removal of maxillary sinus mucosa, radical ethmoidectomy, and sphenoidectomy). The combined approach was applied to maxillary tumors originating lateral to the infraorbital nerve. A medial maxillectomy was performed in all cases with the exception of tumors limited to only the frontal sinus or sphenoid. Complications after surgery were classified according to the Clavien-Dindo Classification of Surgical Complications (Table 1) [10]. All patients were followed up by endoscopy every three months for the first two years. After this period, patients were followed up biannually for up to five years. MRI and/or biopsies were performed when a recurrence was suspected.

A literature search was performed of EMBASE (2005, jan -2016 , dec) using the key term 'inverted papilloma'. All IP case series with a minimal follow-up of 12 months, reporting on recurrence rates per operative approach, and published in the English language were included.

\section{Statistical analysis}

When quantitative variables were normally distributed, the results were expressed as mean values and standard deviation (SD), otherwise median and inter quartile range (IQR). Differences between two groups were analyzed using the t-test or the Mann-Whitney $U$ test. Qualitative data are reported as counts and frequencies, and differences between groups were analyzed using the chi-squared test or Fisher's exact test. Multivariate logistic regression was used to investigate the association of Krouse staging, surgical approach and presentation of tumor and the risk of recurrence [11]. Cox regression analysis was performed to evaluate the association between variables of the univariate analysis and recurrence free survival time. Statistical analysis was performed using SPSS version 21 (IBM Co., Armonk, NY, USA) and cut off point for significance was $p<0.05$.

\section{Results}

The mean age at time of diagnosis was 55.8 years (SD 13.7). The study population consisted of 245 males and 78 females $(3.1,1)$. Nasal obstruction was the most frequent complaint (257 patients, 79.6\%). Other complaints were rhinorrhea $(73,22.6 \%)$, headache $(38,11.8 \%)$, epiphora (21, $6.5 \%)$ and feeling of pressure in the face or forehead (17, $5.3 \%)$. Thirty patients (9.3\%) had no complaints. Preoperative radiological imaging was performed with CT-scan in 201 cases $(62.2 \%)$ and with MRI in 15 cases (4.6\%). Both $\mathrm{CT}$ and MRI were used in 62 patients (19.2\%). Forty-five patients (13.9\%) underwent surgery without preoperative radiological imaging. The left and right side of the

\begin{tabular}{|c|c|}
\hline Grade I & $\begin{array}{l}\text { Any deviation from normale post-operative care without } \\
\text { the need for treatment or interventions }\end{array}$ \\
\hline Grade II & Requiring pharmacological treatment or blood transfusion \\
\hline Grade III & Requiring surgical, endoscopic or radiological intervention \\
\hline Grade IV & Life-treatening complication requiring IC/ICU management \\
\hline Grade V & Death of a patient \\
\hline
\end{tabular}


sinonasal cavity were equally involved (50.2\% vs. $48.3 \%)$. Five patients (1.5\%) had bilateral involvement.

In 121 of the cases (37.5\%) the inverted papilloma was primary, in 115 cases $(35.6 \%)$ residual, and in 87 cases $(26.9 \%)$ recurrent. The tumors were classified as Krouse T1 to T4 in respectively 38 (11.8\%), 148 (45.8\%), 108 (33.4\%) and 29 cases (9.0\%). Twenty-eight IP were classified as T4 because of an associated malignancy and one because of extrasinonasal extension. Endoscopic surgery was performed in 107 patients (33.1\%), a combined approach in 22 cases $(6.8 \%)$ and an external procedure in 194 patients $(60.1 \%)$.

\section{Complications}

The overall percentage of perioperative complications was 14.6\% (47 cases). Most complications were Clavien-Dindo grade I $(24,51.1 \%)$, such as sensibility disorders, perioperatively managed cerebrospinal fluid leakage and excessive crustae. Ten patients (21.3\%), including four wound infections, had grade II complications. Most Clavien-Dindo grade III complications $(10,21.3 \%)$ were complaints of epiphora after a classical Denker procedure that required a dacrocystorhinostomy. Two patients (4.3\%, grade IV) developed meningitis post-operatively and had to be admitted to the intensive care unit. One patient died post-operatively as a result of severe comorbidity $(2.1 \%$, grade $\mathrm{V})$.

\section{Malignancies}

Thirty-one patients (9.6\%) had an associated malignancy. The malignancy occurred synchronously in 28 cases (90.3\%). They consisted of 25 squamous cell carcinomas (89.3\%), two verrucous carcinomas (7.2\%), and one undifferentiated carcinoma (3.6\%). Three other cases squamous cell carcinomas developed metachronously $(9.7 \%)$.

Four patients $(12.9 \%)$ had a carcinoma in situ. Nine patients had tumor with T stage I (29.0\%) three with II (9.7\%), three with III (9.7\%) and 12 with IV (38.7\%). Three patients $(9.7 \%)$ had a regional lymph node metastasis and three patients $(9.7 \%)$ a distant metastasis. Most patients (80.6\%) with an associated malignancy were treated with an external approach. For patients with an associated malignancy, the 5-year overall survival was $80.6 \%$ and the 5-year disease specific survival $87.1 \%$.
Eight patients with an a associated malignancy (25.8\%) developed a recurrent IP after initial treatment. The 5-year recurrence free survival rate was $77.4 \%$. During follow-up 20 patients $(64.5 \%)$ remained alive with no evidence of disease. One (3.2\%) was alive with disease, eight (25.8\%) died of disease, and two (6.5\%) died of other cause.

\section{Recurrence analysis}

We included a sub selection of 247 patients cohort in our recurrence analysis. Sixty-one patient were excluded because their follow up was $<2$ years. Another fifteen patients with suspected residual IP were excluded because postoperative histopathologic examination did not confirm the residual IP. The median follow-up was 66.2 months (IQR 41.1-112.9). Overall recurrences occurred in 74 patients $(30.0 \%)$ (Table 2 ).

\section{Type of surgery}

Seventy-nine $(32.0 \%)$ cases in our recurrence analysis were treated with pure endonasal endoscopic surgery. Recurrences occurred in sixteen endoscopic cases (20.3\%). Primary IP treated endoscopically recurred in three cases (12.5\%), residual IP in eight cases $(25.0 \%)$ and recurrent IP in 5 cases (21.7\%). Four of fourteen patients $(28.6 \%)$ treated with a combined approach developed a recurrence. The majority of the cases had an external procedure $(154,62.3 \%)$. They developed recurrences in 54 cases $(35.1 \%)$. This is significantly higher than the endoscopic group ( $p=0.017$, OR 95 CI 2.3 [1.1-4.4]) (Table 2). Primary tumors treated externally recurred in eighteen cases (26.5\%). For residual $(45.7 \%$, $p=0.028$, OR 95\% CI 2.4 [1.1-5.6]) and recurrent (37.5\%) tumors, this percentage was higher. The distribution of Krouse stage was not significantly different in these groups (Table 3).

\section{Presentation of tumor}

The risk of recurrence was significantly higher in the residual IP group than primary IP (31 [36.9\%] vs 22 [23.2\%], $p=0.021$ OR 95\% CI 2.2 [1.1-4.3]). Recurrence occurred in 21 cases (30.9\%) in the recurrent IP group.

Table 2 Multivariate analysis of recurrence rates according to surgical approach and presentation of the tumor

\begin{tabular}{lllll}
\hline & $\begin{array}{l}\text { Endoscopic approach } \\
\text { No. of recurrences / } \\
\text { total no. of patients (\%) }\end{array}$ & $\begin{array}{l}\text { Combined approach } \\
\text { No. of recurrences / } \\
\text { total no. of patients (\%) }\end{array}$ & $\begin{array}{l}\text { External approach } \\
\text { No. of recurrences / } \\
\text { total no. of patients (\%) }\end{array}$ & $\begin{array}{l}\text { Total } \\
\text { No. of recurrences / } \\
\text { total no. of patients (\%) }\end{array}$ \\
\hline Primary IP & $3 / 24(12.5)$ & $1 / 3(33.3)$ & $18 / 68(26.5)$ & $22 / 95(23.2)$ \\
Residual IP & $8 / 32(25.0)$ & $2 / 6(33.3)$ & $21 / 46(45.7)^{*}$ & $31 / 84(36.9) \dagger$ \\
Recurrent IP & $5 / 23(21.7)$ & $1 / 5(20.0)$ & $15 / 40(37.5)$ & $21 / 68(30.9)$ \\
Total & $16 / 79(20.3)$ & $4 / 14(28.6)$ & $54 / 154(35.1) \neq$ & $74 / 247(30.0)$ \\
\hline
\end{tabular}

${ }^{*} p=0.021$ compared to primary IP treated with external approach. $\dagger p=0.028$ compared to total primary IP. $\neq p=0.017$ compared to total endoscopic approach 
Table 3 Distribution of Krouse stage per surgical approach

\begin{tabular}{lllll}
\hline Krouse stage & $\begin{array}{l}\text { Endoscopic approach } \\
\text { no. of patients (\%) }\end{array}$ & $\begin{array}{l}\text { Combined approach } \\
\text { no. of patients (\%) }\end{array}$ & $\begin{array}{l}\text { External approach } \\
\text { no. of patients (\%) }\end{array}$ & $\begin{array}{l}\text { Total } \\
\text { no. of patients (\%) }\end{array}$ \\
\hline T1 & $15(19.0)$ & $0(0.0)$ & $13(8.4)$ & $28(11.3)$ \\
T2 & $39(49.4)$ & $2(14.3)$ & $75(48.7)$ & $116(47.0)$ \\
T3 & $22(27.8)$ & $11(78.6)$ & $49(31.8)$ & $82(33.2)$ \\
T4 & $3(3.8)$ & $1(7.1)$ & $17(11.0)$ & $21(8.5)$ \\
Total & $79(100.0)$ & $14(100.0)$ & $154(100.0)$ & $247(100.0)$ \\
\hline
\end{tabular}

\section{Krouse stage}

Krouse stage did not influence the overall recurrence rate significantly. Patients with Krouse stage T1-T4 IP developed recurrences in respectively 7 (22.6\%), 36 (30.5\%), 25 (28.9\%), and $6(42.9 \%)$ cases.

\section{Time to recurrence}

The median time to recurrence was 20.5 months (IQR 11.8-37.5). The surgical approach and the presentation of the tumor had no significant influence on the time to recurrence. Table 4 gives an overview of when the recurrences occur during follow-up. Only forty-one (55.4\%) of all recurrences were diagnosed in the first two years of follow-up. More than $80 \%$ (58) of all recurrences were diagnosed within four years.

\section{Number of recurrences}

Thirty-seven (50\%) of all 74 cases with a recurrence after initial surgery in our hospital developed a second recurrence after revision surgery. This occurred more often in the group of patients that underwent external surgery than the endoscopic group (5/16 [31.3\%] vs. 32/54 [59.3\%], $p=0.049)$. Eighteen patients $(24.3 \%)$ developed a third recurrence, while six patients $(8.1 \%)$ developed even more than three recurrences during follow-up.

\section{Literature review}

A total of 64 articles IP cohort-studies between 2005 and 2016 were found, of which 23 articles with a total of 1989 patients met the inclusion criteria (Table 5) [12-34]. Their mean follow-up was 54.5 months. Of the 1433 patients treated endoscopically $161(11.2 \%)$ developed a recurrence. Recurrence rates reported varied between $0.0 \%$ and $30.0 \%$. Seven articles reported a total of $32(12.3 \%)$ recurrences in 260 patients treated with a combined approach. Fifty-four (18.2\%) recurrences occurred in a total of 296 external procedures. Fourty-one articles did not meet the inclusion criteria.

\section{Discussion}

We have, to our knowledge, presented the largest ever single-center cohort of inverted papilloma patients. Our reported recurrence rates were higher for residual and recurrent IP than primary IP. We also confirmed superiority of endoscopic surgery over combined and external approaches. Finally, we've shown that many recurrences occur more than two years after initial treatment.

Thirty percent of all the patients in our recurrence analysis developed a recurrence (Table 2). This is relatively high compared to recent literature (Table 4). This could be explained by our heterogeneous cohort with a high number (62.3\%) of external surgery. Also our rate is based on results covering a large time period with one third of the patients treated before the 'endoscopic era'. These patients account for more than half of all recurrences. Based on our observation, most of the recurrences after an external approach, Denker in particular, occur in the frontal recess and ethmoidal roof. Tumor remnants at these areas can easily be missed or left out during such procedures due to lack of good visualization and

Table 4 Time to recurrence

\begin{tabular}{|c|c|c|c|}
\hline \multirow[t]{2}{*}{ Follow-up } & Endoscopic approach $(n=79)$ & Combined approach $(n=14)$ & External approach $(n=154)$ \\
\hline & $\begin{array}{l}\text { No. of recurrences / } \\
\text { total no. of recurrences (\%) }\end{array}$ & $\begin{array}{l}\text { No. of recurrences / } \\
\text { total no. of recurrences (\%) }\end{array}$ & $\begin{array}{l}\text { No. of recurrences / } \\
\text { total no. of recurrences (\%) }\end{array}$ \\
\hline$<1$ year & $5 / 16(31.3)$ & $0 / 4(0.0)$ & $16 / 54$ (29.6) \\
\hline$<2$ year & $11 / 16(68.8)$ & $3 / 4(75.0)$ & $27 / 54(50.0)$ \\
\hline$<3$ year & 13 / 16 (81.3) & 4 / 4 (100.0) & 38 / 54 (70.4) \\
\hline$<4$ year & $13 / 16$ (81.3) & & 44 / 54 (81.5) \\
\hline$<5$ year & $13 / 16(81.3)$ & & 45 / 54 (83.3) \\
\hline 6-10 year & 16 / $16(100.0)$ & & $51 / 54$ (94.4) \\
\hline$>10$ year & & & 54 / 54 (100.0) \\
\hline
\end{tabular}


Table 5 Review of inverted papilloma cohort studies per surgical approach with a minimal follow-up of 12 months (2005-2016)

\begin{tabular}{|c|c|c|c|c|c|c|c|c|c|c|}
\hline \multirow{3}{*}{$\begin{array}{l}\text { Authors } \\
\text { Poetker et al. [12] }\end{array}$} & \multirow{3}{*}{$\begin{array}{l}\text { Year published } \\
2005\end{array}$} & \multirow{2}{*}{\multicolumn{2}{|c|}{$\begin{array}{l}\begin{array}{l}\text { Endoscopic } \\
\text { approach }\end{array} \\
\text { No. of recurrences / \%) }\end{array}$}} & \multirow{2}{*}{\multicolumn{2}{|c|}{$\begin{array}{l}\text { Combined } \\
\text { approach } \\
\text { No. of recurrences / } \\
\text { total no. of patients (\%) }\end{array}$}} & \multirow{2}{*}{\multicolumn{2}{|c|}{$\begin{array}{l}\begin{array}{l}\text { External } \\
\text { approach }\end{array} \\
\text { No. of recurrences / } \\
\text { total no. of patients (\%) }\end{array}$}} & \multicolumn{3}{|c|}{$\begin{array}{l}\text { Follow-up } \\
\text { (months) }\end{array}$} \\
\hline & & & & & & & & \multirow{2}{*}{$\begin{array}{l}\text { Mean } \\
29.8\end{array}$} & \multirow{2}{*}{$\begin{array}{l}\text { Low } \\
12\end{array}$} & \multirow{2}{*}{$\begin{array}{l}\text { High } \\
80\end{array}$} \\
\hline & & $0 / 8$ & $(0.0)$ & $1 / 4$ & $(25.0)$ & & & & & \\
\hline Kamel et al. [13] & 2005 & $3 / 52$ & $(5.8)$ & & & & & 65 & 24 & 160 \\
\hline Peng et al. [14] & 2006 & & & & & $2 / 98$ & $(2.0)$ & 61 & 24 & 168 \\
\hline Minovi et al. [15] & 2006 & $6 / 61$ & (9.8) & $3 / 20$ & $(15.0)$ & $0 / 6$ & $(0.0)$ & 74 & 12 & 175 \\
\hline Mirza et al. [16] & 2007 & $4 / 32$ & $(12.5)$ & & & $4 / 16$ & $(25.0)$ & 60 & 12 & 240 \\
\hline Harvinder et al. [17] & 2008 & $0 / 5$ & $(0.0)$ & & & & & 23 & 12 & 36 \\
\hline Jurado-ramos et al. [18] & 2008 & $4 / 34$ & $(11.8)$ & & & $8 / 18$ & $(44.4)$ & 54.3 & 12 & 60 \\
\hline Durucu et al. [19] & 2009 & $2 / 23$ & $(8.7)$ & $1 / 14$ & (7.1) & $3 / 19$ & $(15.8)$ & 35 & 16 & 42 \\
\hline Sham et al. [20] & 2009 & $12 / 40$ & $(30.0)$ & & & $6 / 16$ & $(37.5)$ & 84 & 24 & 216 \\
\hline Rutherford et al. [21] & 2010 & $0 / 2$ & $(0.0)$ & & & & & 19 & 15 & 24 \\
\hline Giotakis et al. [22] & 2010 & $5 / 39$ & $(12.8)$ & & & $11 / 25$ & $(44.0)$ & 91 & 36 & 146 \\
\hline Gras-Cabrerizo et al. [23] & 2010 & $10 / 57$ & $(17.5)$ & & & $7 / 22$ & $(31.8)$ & & 12 & \\
\hline Pagella et al. [24] & 2011 & $1 / 20$ & $(5.0)$ & & & & & 50 & 24 & 87 \\
\hline Dragonetti et al. [25] & 2011 & $5 / 84$ & $(6.0)$ & & & & & 39 & 13 & 97 \\
\hline Lombardi et al. [26] & 2011 & $12 / 198$ & $(6.1)$ & $0 / 14$ & $(0.0)$ & & & 53.8 & 24 & 192 \\
\hline Kim et al. [27] & 2012 & $64 / 372$ & $(17.2)$ & $17 / 144$ & $(11.8)$ & $10 / 62$ & $(16.1)$ & 41 & 12 & \\
\hline Pagella et al. [28] & 2014 & $1 / 73$ & $(1.4)$ & & & & & 58 & 18 & 138 \\
\hline Sciaretta et al. [29] & 2014 & $7 / 103$ & (6.8) & & & & & 57.7 & 24 & 167 \\
\hline Gu et al. [30] & 2014 & $1 / 7$ & $(14.3)$ & & & $3 / 14$ & $(21.4)$ & 65 & 36 & 144 \\
\hline Erbek [31] & 2015 & $0 / 8$ & $(0.0)$ & & & & & 30.8 & 12 & 60 \\
\hline Hong [32] & 2015 & $0 / 6$ & $(0.0)$ & $3 / 25$ & $(12.0)$ & & & 55.6 & 36 & 93 \\
\hline Adriaensen [33] & 2016 & $15 / 121$ & $(12.4)$ & $7 / 39$ & (17.9) & & & & 12 & 139 \\
\hline Healy [34] & 2016 & $9 / 88$ & $(10.2)$ & & & & & 97.2 & 36 & \\
\hline Total & & $161 / 1433$ & $(11.2)$ & 32 / 260 & (12.3) & $54 / 296$ & $(18.2)$ & 54.5 & & \\
\hline
\end{tabular}

magnification. Nowadays, we make it a point to inspect these areas using an endoscope and drill out as much bone as possible. Several literature reviews on IP recurrences have been published between 1981 and 2009 [9, 14, 35-37]. Their average recurrence rates after endoscopic surgery vary between $12.5 \%$ and $19.6 \%$. This is higher than the $11.3 \%$ in our review of more recent studies, suggesting a global decrease in recurrence rates in endoscopic IP surgery.

Our recurrence in the endoscopic group (20.3\%) was also higher than the average $11.2 \%(161 / 1433)$ in our review of the recent literature (Table 5). However, primary tumors treated by endoscopically had a similar recurrence rate of $12.5 \%$. Therefore, we believe that the relatively high recurrence rate is due to our high number of residual and recurrent IP and to our long follow (median $>$ six years). After splitting the complete endoscopic group in a 2003-2007 (the first years of endoscopic IP surgery in our clinic) and a 2008-2012 cohort, we also noted a non-significant learning curve is noticed with $31.8 \%$ and $15.4 \%$ recurrences $(p=0.12)$ respectively.

A wide range of recurrence rates $(0.0-45.0 \%)$ have been documented after revision surgery (Table 6) [20, $26-29,33,38-40]$. However, it is generally accepted that it has a worse outcome than primary surgery, which is support that functional endoscopic sinus surgery should not be used as a diagnostic tool for unilateral sinonasal disease (a pre-operative biopsy should). The worse outcome of revision IP surgery has been explained due to the increased difficulty to identify the attachment site of the IP because of distorted anatomy and the absence of landmarks [33, 41, 42]. Post-operative inflammation of the remaining sinonasal mucosa could also attribute to this due to an increased difficulty to distinguish normal mucosa from tumor. This is most evident in patients with a residual IP due to the relative short time between primary and revision surgery. It could even be that incomplete surgery has an effect on the inflammatory 
Table 6 Recurrence rates according to presentation of the tumor in eight cohort studies

\begin{tabular}{|c|c|c|c|c|c|}
\hline \multirow[t]{2}{*}{ Authors } & \multirow[t]{2}{*}{ Year published } & \multicolumn{2}{|c|}{ Primary cases } & \multicolumn{2}{|c|}{ Revision cases } \\
\hline & & \multicolumn{2}{|c|}{$\begin{array}{l}\text { No. of recurrences / } \\
\text { total no. of patients (\%) }\end{array}$} & \multicolumn{2}{|c|}{$\begin{array}{l}\text { No. of recurrences / } \\
\text { total no. of patients (\%) }\end{array}$} \\
\hline Tufano et al. [40] & 1999 & $1 / 17$ & $(5,9)$ & $4 / 16$ & $(23,2)$ \\
\hline Han et al. [39] & 2001 & $0 / 14$ & $(0,0)$ & $3 / 17$ & $(17,6)$ \\
\hline Lee et al. [38] & 2004 & & & $3 / 17$ & $(17,6)$ \\
\hline Sham et al. [20] & 2009 & $9 / 36$ & $(25,0)$ & $9 / 20$ & $(45,0)$ \\
\hline Lombardi et al. [26] & 2011 & $8 / 156$ & $(5,1)$ & $4 / 56$ & $(7,1)$ \\
\hline Kim et al. [27] & 2012 & $70 / 456$ & $(15,4)$ & $21 / 122$ & $(17,2)$ \\
\hline Pagella et al. [28] & 2014 & $1 / 64$ & $(1,6)$ & $0 / 7$ & $(0,0)$ \\
\hline Sciarretta et al. [29] & 2014 & $0 / 57$ & $(0,0)$ & $7 / 53$ & $(13,2)$ \\
\hline Gu [30] & 2014 & & & $4 / 21$ & (19.0) \\
\hline Adriaensen et al. [33] & 2015 & $2 / 49$ & $(4,1)$ & $13 / 72$ & $(18,1)$ \\
\hline
\end{tabular}

pathway of the etiology and progression of IP, possibly explaining multi-centered recurrent IP.

Many articles claim that the majority of recurrences after IP-surgery occur in the first two years [20, 43]. Sham et al. published a detailed data of time to recurrences of a group of 56 patients, which supported this statement [20]. This was however not the case in our larger cohort: only $55.4 \%$ of all recurrences occurred in the first two years (Table 4). This percentage was slightly higher $(68.8 \%)$ in patient treated endoscopically. A follow-up of three years after endoscopic surgery and four years for all cases was needed to diagnose $>80 \%$ of the recurrences. A multi-center study has also shown a significant difference in recurrence rate between patients with a follow-up longer and shorter than three years (26.1 vs. 8.5\%) [27]. Therefore, our department supports suggestions by Suh and Adriaensen to perform a long or even life-time clinical follow-up [33, 43].

\section{Conclusion}

The recurrence rate of residual tumors is significantly higher than primary tumors. Therefore clinicians should have a low threshold for suspecting IP and when uncertain first take a biopsy. Furthermore, given the mean time to recurrence and the rate of late recurrences a long followup is required in both the clinic and research.

\section{Abbrevation \\ IP: Inverted papilloma}

\section{Acknowledgements}

The authors thank Thijs Hooft van Huysduynen and Marjan van den Brink for their help initiating this study.

\section{Funding}

This study did not receive any funding.

\section{Availability of data and materials}

The datasets used and/or analysed during the current study are available from the corresponding author on reasonable request.

\section{Authors' contributions}

$\mathrm{OB}, \mathrm{DM}$ and $\mathrm{JH}$ contributed to study conception. All authors contributed to the study design. OB and FvZ performed the data collection. OB, FvZ, DM and $\mathrm{JH}$ or supervised data analysis. All authors interpreted the data. $\mathrm{OB}$ and DM wrote sections of the initial manuscript. OB designed figures and tables. All authors critically reviewed iterations of the manuscript and approved the final draft for submission.

\section{Competing interests}

All authors declare that they have no conflicts of interest.

\section{Consent for publication}

Not applicable.

\section{Ethics approval and consent to participate}

The Ethics Committee of the Erasmus Medical Center, a tertiary referral medical center, stated that ethical permission was not required for this retrospective study.

\section{Publisher's Note}

Springer Nature remains neutral with regard to jurisdictional claims in published maps and institutional affiliations.

Received: 7 July 2017 Accepted: 6 December 2017

Published online: 20 December 2017

\section{References}

1. Ward N. Follicular tumour involving the nasal bones, nasal processes of the superior maxillary bone, and the septum of the nose; removal; death from pneumonia; autopsy. Lancet. 1854;2:480-2.

2. Ringertz N. Pathology of malignant tumors arasing in nasal and paranasal cavities and maxilla. Acta Otolaryngol. 1938;27:31-42.

3. Eggers G, Muhling J, Hassfeld S. Inverted papilloma of paranasal sinuses. J Craniomaxillofac Surg. 2007;35(1):21-9.

4. Melroy $C T$, Senior BA. Benign sinonasal neoplasms: a focus on inverting papilloma. Otolaryngol Clin N Am. 2006;39(3):601-17.

5. Govindaraj S, Wang H. Does human papilloma virus play a role in sinonasal inverted papilloma? Curr Opin Otolaryngol Head Neck Surg. 2014;22(1):47-51.

6. Strojan P, Ferlito A, Lund VJ, et al. Sinonasal inverted papilloma associated with malignancy: the role of human papillomavirus infection and its implications for radiotherapy. Oral Oncol. 2012;48(3):216-8.

7. van den Boer C, Brutel G, de Vries N. Is routine histopathological examination of FESS material useful? Eur Arch Otorhinolaryngol. 2010;267(3):381-4.

8. Garavello W, Gaini RM. Histopathology of routine nasal polypectomy specimens: a review of 2,147 cases. Laryngoscope. 2005;115(10):1866-8.

9. Busquets JM, Hwang PH. Endoscopic resection of sinonasal inverted papilloma: a meta-analysis. Otolaryngol Head Neck Surg. 2006;134(3):476-82. 
10. Dindo D, Demartines N, Clavien PA. Classification of surgical complications: a new proposal with evaluation in a cohort of 6336 patients and results of a survey. Ann Surg. 2004;240(2):205-13.

11. Krouse JH. Development of a staging system for inverted papilloma. Laryngoscope. 2000;110(6):965-8.

12. Poetker DM, Toohill RJ, Loehrl TA, et al. Endoscopic management of sinonasal tumors: a preliminary report. Am J Rhinol. 2005;19(3):307-15.

13. Kamel R, Khaled A, Kandil T. Inverted papilloma: new classification and guidelines for endoscopic surgery. Am J Rhinol. 2005;19(4):358-64.

14. Peng P, Har-El G. Management of inverted papillomas of the nose and paranasal sinuses. Am J Otolaryngol. 2006;27(4):233-7.

15. Minovi A, Kollert M, Draf W, et al. Inverted papilloma: feasibility of endonasal surgery and long-term results of 87 cases. Rhinolog. 2006;44(3):205-10.

16. Mirza S, Bradley PJ, Acharya A, et al. Sinonasal inverted papillomas: recurrence, and synchronous and metachronous malignancy. J Laryngol Otol. 2007;121(9):857-64.

17. Harvinder S, Rosalind S, Mallina S, et al. Management of sinonasal inverted papillomas: endoscopic medial maxillectomy. Med J Malaysia. 2008;63(1):58-60.

18. Jurado-Ramos A, Jodas JG, Romero FR, et al. Endoscopic medial maxillectomy as a procedure of choice to treat inverted papillomas. Acta Otolaryngol. 2009;129(9):1018-25.

19. Durucu C, Baglam T, Karatas E, et al. Surgical treatment of inverted papilloma. J Craniofac Surg. 2009;20(6):1985-8.

20. Sham CL, Woo JK, van Hasselt CA, et al. Treatment results of sinonasal inverted papilloma: an 18-year study. Am J Rhinol Allergy. 2009;23(2):203-11.

21. Rutherford KD, Brown SM. Endoscopic resection of maxillary sinus inverted papillomas with inferior turbinate preservation. Otolaryngol Head Neck Surg. 2010;142(5):760-2.

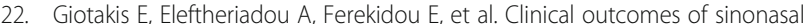
inverted papilloma surgery. A retrospective study of 67 cases. B-Ent. 2010; 6(2):111-6.

23. Gras-Cabrerizo JR, Montserrat-Gili JR, Massegur-Solench $\mathrm{H}$, et al. Management of sinonasal inverted papillomas and comparison of classification staging systems. Am J Rhinol Allergy. 2010;24(1):66-9.

24. Pagella F, Giourgos G, Matti E, et al. Endoscopic treatment of maxillary inverted papilloma. Rhinology. 2011;49(3):369-74.

25. Dragonetti A, Gera R, Sciuto A, et al. Sinonasal inverted papilloma: 84 patients treated by endoscopy and proposal for a new classification. Rhinology. 2011;49(2):207-13.

26. Lombardi D, Tomenzoli D, Butta L, et al. Limitations and complications of endoscopic surgery for treatment for sinonasal inverted papilloma: a reassessment after 212 cases. Head Neck. 2011;33(8):1154-61.

27. Kim DY, Hong SL, Lee CH, et al. Inverted papilloma of the nasal cavity and paranasal sinuses: a Korean multicenter study. Laryngoscope. 2012;122(3):487-94.

28. Pagella F, Pusateri A, Giourgos G, et al. Evolution in the treatment of sinonasal inverted papilloma: pedicle-oriented endoscopic surgery. Am J Rhinol Allergy. 2014;28(1):75-81.

29. Sciarretta V, Fernandez IJ, Farneti $P$, et al. Endoscopic and combined externaltransnasal endoscopic approach for the treatment of inverted papilloma: analysis of 110 cases. Eur Arch Otorhinolaryngol. 2014:271(7):1953-9.

30. Gu FM, Zhang LS. Clinical outcomes of endoscopic and open resection of recurrent sinonasal inverted papilloma. J Craniofac Surg. 2014;25(3):1090-3.

31. Erbek SS, Koycu A, Buyuklu F. Endoscopic modified medial maxillectomy for treatment of inverted papilloma originating from the maxillary sinus. J Craniofac Surg. 2015;26(3):e244-6.

32. Hong SL, Mun SJ, Cho KS, et al. Inverted papilloma of the maxillary sinus: surgical approach and long-term results. Am J Rhinol Allergy. 2015;29(6):441-4

33. Adriaensen GF, Lim KH, Georgalas C, et al. Challenges in the Management of Inverted Papilloma: a review of 72 revision cases. Laryngoscope. 2016;126(2):322-8.

34. Healy DY Jr, Chhabra N, Metson R, et al. Surgical risk factors for recurrence of inverted papilloma. Laryngoscope. 2016;126(4):796-801.

35. Karkos PD, Fyrmpas G, Carrie SC, et al. Endoscopic versus open surgical interventions for inverted nasal papilloma: a systematic review. Clin Otolaryngol. 2006;31(6):499-503.

36. Philpott CM, Dharamsi A, Witheford $M$, et al. Endoscopic management of inverted papillomas: Iong-term results-the St. Paul's sinus Centre experience. Rhinology. 2010:48(3):358-63.

37. Heathcote KJ, Nair SB. The impact of modern techniques on the recurrence rate of inverted papilloma treated by endonasal surgery. Rhinology. 2009; 47(4):339-44.
38. Lee TJ, Huang SF, Lee LA, et al. Endoscopic surgery for recurrent inverted papilloma. Laryngoscope. 2004;114(1):106-12. https://www.ncbi.nlm.nih.gov/ pubmed/14710004.

39. Han JK, Smith TL, Loehrl T, et al. An evolution in the management of sinonasal inverting papilloma. Laryngoscope. 2001;111(8):1395-400.

40. Tufano RP, Thaler ER, Lanza DC, et al. Endoscopic management of sinonasal inverted papilloma. Am J Rhinol. 1999;13(6):423-6.

41. Lawson W, Patel ZM. The evolution of management for inverted papilloma: an analysis of 200 cases. Otolaryngol Head Neck Surg. 2009;140(3):330-5.

42. Lund VJ, Stammberger $\mathrm{H}$, Nicolai $\mathrm{P}$, et al. European position paper on endoscopic management of tumours of the nose, paranasal sinuses and skull base. Rhinol Suppl. 2010;22:1-143.

43. Suh JD, Chiu AG. What are the surveillance recommendations following resection of sinonasal inverted papilloma? Laryngoscope. 2014;124(9):1981-2.

\section{Submit your next manuscript to BioMed Central and we will help you at every step:}

- We accept pre-submission inquiries

- Our selector tool helps you to find the most relevant journal

- We provide round the clock customer support

- Convenient online submission

- Thorough peer review

- Inclusion in PubMed and all major indexing services

- Maximum visibility for your research

Submit your manuscript at www.biomedcentral.com/submit
C) Biomed Central 